\title{
QUESTÕES DE MÉTODO EM TEXTOS DE VYGOTSKI: CONTRIBUIÇÕES À PESQUISA EM PSICOLOGIA
}

\author{
Andréa Vieira Zanella \\ Alice Casanova dos Reis \\ Andréia Piana Titon \\ Lílian Caroline Urnau \\ Tais Rodrigues Dassoler \\ Universidade Federal de Santa Catarina, Florianópolis, Brasil
}

\begin{abstract}
RESUMO: Este artigo, de natureza eminentemente teórica, discute algumas reflexões metodológicas que permearam o desenvolvimento das pesquisas de Lev S. Vygotski e disseminam-se por toda a sua obra. Como procedimento selecionou-se alguns textos dos três primeiros volumes de suas Obras Escolhidas, edição espanhola, nos quais foram identificadas as seguintes unidades temáticas de análise: a relação problema/método/técnicas de investigação; a relação singular/coletivo e suas implicações metodológicas; a história e a dialética como fundamentos metodológicos; princípios do método; busca dos sentidos como unidade de análise da psicologia histórico-cultural. As reflexões aqui apresentadas podem ser úteis para pesquisadores contemporâneos que compartilham as concepções ontológicas e epistemológicas da Psicologia histórico-cultural.
\end{abstract}

PALAVRAS-CHAVE: Vygotski; método; questões metodológicas; pesquisa; Psicologia histórico-cultural.

\section{METHOD ISSUES IN VYGOTSKY'S TEXTS: CONTRIBUTIONS TO PSYCHOLOGY RESEARCH}

ABSTRACT: This article, of an eminently theoretical nature, discusses some methodological issues that permeated the development of Lev S. Vygotski's research and spread throughout his work. To undertake this discussion, some texts from the first three volumes of his Complete Works, Spanish Edition, were chosen for analysis, from which the following thematic units were identified: the relationship between problem/method/inquiry techniques; the singular/ collective relationship and its methodological implications; history and dialectics as methodological fundamentals; method principles; search of the senses as unit of analysis of historical-cultural Psychology. The reflections presented here can be useful for contemporary researchers who share the ontological and epistemological conceptions of historical-cultural Psychology.

KEYWORDS: Vygotski; method; methodological issues; research; Historical-cultural Psychology.

Existem dois procedimentos metodológicos distintos para as investigações psicológicas concretas. Em um deles a metodologia da investigação se expõe separadamente da própria investigação. Em outro, está presente em toda a investigação. Poderíamos citar vários exemplos de um e de outro. Alguns animais - os de corpo mole - levam seu esqueleto externamente assim como o caracol leva a concha; outros tem seu esqueleto dentro, internamente. Esse segundo tipo de estrutura nos parece superior não somente para os animais como também para as monografias psicológicas e por isso a escolhemos (Vygotski, 1995, p. 28).

A psicologia de Lev Semionovitch Vygotski vem se consolidando no cenário científico como referência em pesquisas que discutem o processo de constituição do sujeito em diferentes contextos e condições sociais. A difusão de sua obra no Brasil, obra esta predominantemente voltada para a explicação do movimento complexo em que, via mediação semiótica, o psiquismo humano é social e historicamente constituído, aconteceu inicialmente no campo educacional, sendo seus estudos utilizados como referência para pesquisas e propostas que buscavam transcender tanto as vertentes ambientalistas quanto as teorias individualizantes presentes no ideário educacional (Davis \& Oliveira, 1994; Kramer \& Souza, 1991; Pino, 1992).

A psicologia brasileira, por sua vez, inicia o processo de aproximação com o legado vygotskiano em meados da década de 80 do século $\mathrm{XX}$, aproximação esta que se intensifica na década seguinte. Retrato dessa aproximação é o número de teses e dissertações defendidas junto a Programas Brasileiros de Pós-Graduação em Psicologia que utilizam o referencial do autor russo. A utilização dos aportes vygotskianos nas produções científicas da área psi parece, de certa forma, consolidada, apresentando-se como perspectiva teórico-conceitual que traz relevantes contribuições ao desenvolvimento da psicologia e suas variadas práticas.

No que se refere às questões metodológicas, no entanto, há aspectos importantes das contribuições de Vygotski que precisam ser discutidos/explicitados, aspectos esses 
que se apresentam no conjunto dos escritos do autor, dispersos aqui e acolá, compondo um firme esqueleto que, como esclarece o próprio Vygotski na epígrafe que inaugura este texto, sustenta todas as investigações que realizou. Esse esqueleto, ao mesmo tempo (in)visível e onipresente, pouco é discutido nas produções científicas que explicitam utilizar a Psicologia Histórico-Cultural como fundamento.

A pesquisa em bases de dados com o descritor Vygostki (em quatro variações de ortografia, trocando-se as letras $y$ e $i$ ) evidencia um aumento considerável da produção científica referenciada nas contribuições do autor, a partir do ano de 2000: foram localizadas 449 produções científicas nas bases de dados disponibilizadas pelo Portal CAPES (Webspirs - psycINFO; Scopus Find Out e Google Shoolar Beta) e nas coleções Gale e Ovid, ${ }^{1}$ em consulta realizada em 01/09/2006. Também foram encontrados sete artigos no Portal CAPES de periódicos nacionais de psicologia.

Ao se apresentar o descritor Vygotski (em quatro variações de ortografia) conjuntamente com os descritores method e/ou methodology, porém, o resultado obtido nas mesmas bases de dados, em consulta realizada no dia 01/ 09/2006, foi significativamente menor: 28 produções científicas foram localizadas, sendo que apenas três realmente discorrem sobre o método, a saber, "Activating postmodernism" (Holzman, 2006), "The formation experiment in the hypermedia and distance learning" (Giest, 2004) $\mathrm{e}$ "Seeing historically: Goethe and Vygotsky's 'enabling theory-method"' (Shotter, 2000).

O primeiro texto trata de relacionar o método dialético e a teoria da atividade de Marx, Vygotski e a filosofia de Wittgenstein com a psicologia pós-moderna. $\mathrm{O}$ segundo texto procura verificar a aplicação do método genéticoexperimental de Vygotski à investigação da formação do pensamento teórico na aprendizagem à distância com hipermídia. E o terceiro, relaciona os métodos históricos de Vygotski e Goethe na investigação do movimento de formas e processos psicológicos e cognitivos vivos na atividade infantil. Ressalta-se que no Portal CAPES de periódicos nacionais de psicologia não foi encontrada nenhuma produção com a intersecção dos descritores Vygotsky, em suas diferentes grafias, e método ou metodologia.

Considerando a importância de resgatar as contribuições de Vygotski no que se refere ao processo de produção de conhecimentos, é objetivo deste texto, de natureza eminentemente teórica, apresentar e discutir algumas de suas afirmações que são indicativas das reflexões metodológicas que permearam o desenvolvimento de suas pesquisas e a construção de seu arcabouço teórico. Essa discussão, por sua vez, será feita à luz das preocupações características de pesquisas realizadas em contextos de pós-graduação, preocupações essas que permeiam a con- dição das autoras, seja porque pesquisam, seja porque orientam o processo de pesquisar. Orientadora e orientandas encontram-se, assim, conjuntamente mobilizadas pelo compromisso de produzir algum conhecimento que se apresente como relevante no cenário da psicologia atual, mais especificamente em sua vertente histórico-cultural. Vinculadas se encontram, assim como é necessário reconhecer a inexorável vinculação entre pesquisador e realidade que se busca investigar, entre epistemologia e metodologia, entre desejos e escolhas.

Essas escolhas, se por um lado demarcam singularidades e, nesse sentido, diferenças, por outro se unificam a partir do lugar teórico que pautam as posturas no processo de pesquisar, as preferências e possibilidades de aproximações assim como os distanciamentos necessários. Explicitar esse lugar é fundamental no trabalho de todo e qualquer pesquisador/orientador/orientando, pois contribui para a localização tanto de quem fala quanto de quem escuta em relação ao que é dito e silenciado.

As reflexões aqui apresentadas podem, portanto, ser úteis para pesquisadores contemporâneos que compartilham as concepções ontológicas e epistemológicas características da psicologia histórico-cultural e se dedicam à produção de conhecimentos que lhe são consoantes.

\section{O caminho trilhado no processo de construção das reflexões aqui apresentadas}

Um aspecto característico da obra de Vygotski, reconhecido por muitos de seus interlocutores contemporâneos, como por exemplo Pino (2005), é a imprecisão conceitual que se caracteriza pela utilização indiferente de variados significantes para se referir aos mesmos processos. A compreensão das explicações que apresenta sobre algo, como por exemplo a mediação semiótica do psiquismo humano, dissemina-se no conjunto de sua obra, o que dificulta a sua compreensão. Ao mesmo tempo, a imprecisão conceitual referida, no exemplo citado, é representada pelos vários conceitos de signo que o autor apresenta, marcados por linguagens diferenciadas e, não raro, incongruentes.

As reflexões metodológicas apresentadas por Vygotski seguem a mesma direção: disseminam-se por toda a sua obra, sendo necessário um esforço para apreender suas contribuições nesse campo. Exemplo disso encontra-se nos cinco primeiros capítulos do volume três das Obras Escogidas (Vygotski, 1995): o segundo intitula-se "método", porém as referências claras a procedimentos de pesquisa são apresentadas no capítulo seguinte, intitulado "Análisis de las funciones psíquicas superiores". Para a leitura deste texto, por sua vez, necessário se faz compreender o conjunto de suas preocupações e também os seus principais interlocutores, o que transforma o processo de 
aproximação às contribuições de Vygotski uma tarefa que não se esgota nas primeiras leituras ou mesmo no recorte de determinados textos desconsiderando-se a totalidade de sua produção.

Embora cientes dessas dificuldades, decidimos enfrentar a tarefa de apresentar algumas das reflexões metodológicas de Vygotski, pois reconhecemos que sua contribuição a esse campo transcende o seu próprio tempo e se apresentam ainda hoje como referências importantes para as pesquisas em psicologia. Para tanto, selecionamos intencionalmente algumas produções do autor que constam nos três primeiros volumes de suas Obras Escogidas, edição espanhola,coletânea que reúne textos de diferentes momentos da produção de Vygotski, a saber:

1. O significado histórico da crise da psicologia, obra escrita em 1927 e publicada pela primeira vez em Obras escolhidas I.

2. Os cinco capítulos que o autor dedica à reflexão sobre as "funções psíquicas superiores" publicados no volume III das Obras Escogidas e intitulados: Cap. 1 O problema do desenvolvimento das funções psíquicas superiores; Cap. 2 - Método de investigação; Cap. 3 - Análise das funções psíquicas superiores; Cap. 4 Estrutura das funções psíquicas superiores; Cap. 5 Gênese das funções psíquicas superiores.

3. Por fim, trabalhamos com o último texto escrito por Vygotski, "Pensamento e Palavra", texto este escrito em 1934 e que foi publicado no ocidente pela primeira vez em 1962 (Lúria, 1988). Adotamos para análise a versão espanhola publicada no volume II das Obras Escogidas.

A seleção desses textos foi possível com a leitura prévia do conjunto de textos publicados nas Obras Escogidas. Após essa primeira leitura procedemos à releitura dos textos selecionados, desta vez com o olhar voltado para as questões metodológicas que ali apareciam. Dessa leitura identificamos as seguintes unidades temáticas para análise: a relação problema/método/técnicas de investigação; a relação singular/coletivo e suas implicações metodológicas; a história e a dialética como fundamentos metodológicos; princípios do método; busca dos sentidos como unidade de análise da psicologia histórico-cultural. A apresentação das análises seguirá justamente essa seqüência de temáticas.

Sobre a relação problema, método e técnicas de investigação

$\mathrm{O}$ texto "O significado histórico da crise da psicologia, uma investigação metodológica" (1991) é um momento importante na obra de Vygotski. A partir de uma análise metateórica da psicologia, o autor investigou criticamente a crise na psicologia como derivada de uma crise nos fundamentos metodológicos da ciência, marcada pela luta entre tendências materialistas, mecanicistas e idealistas, tanto na Europa quanto na Rússia. Observamos a preocupação epistemológica que perpassa o texto, uma vez que o autor examinou as diferentes abordagens teóricometodológicas que configuravam o terreno da psicologia de sua época, perguntando-se sobre qual era o objeto da psicologia e sobre a melhor forma de investigá-lo.

Vygostki, a partir da análise empreendida, concluiu que as diferentes propostas não ofereciam base para uma psicologia geral, uma vez que trabalhavam com diferentes objetos e por diferentes caminhos, ora numa tendência materialista mecanicista, ora idealista, sendo que ambas podem ser caracterizadas como tendências metafísicas em contraposição a uma psicologia concreta. Para superar essa crise, era necessária a criação de uma psicologia geral, social e dialética, onde a investigação do humano superasse a determinação mecanicista da materialidade sobre o homem sem, contudo, encerrá-lo nos desmandes de uma instância intrapsíquica individual.

Na criação dessa psicologia, necessário se fazia redefinir seu objeto, delineando de modo claro o problema a partir do qual o ser humano poderia ser investigado em sua totalidade, assim como o método apropriado para tanto. A relação mutuamente constitutiva entre problema e método, também fora apontada por Vygostski em outros textos, como nessa passagem: “ “... toda apresentação fundamentalmente nova dos problemas científicos, conduz inevitavelmente a novos métodos e técnicas de investigação. O objeto e o método de investigação mantém uma relação muito estreita" (Vygotski, 1995, p. 47).

É de fundamental importância que, no processo de pesquisar, se atente para essa relação, pois o modo como o pesquisador se acerca dos fatos que pretende estudar, elaborando-os em forma de problema de pesquisa, já traz consigo, no olhar lançado sobre a realidade, um filtro metodológico, um olhar que deverá ser refinado para a construção do caminho que se propõe trilhar na sua investigação. Consoante o autor:

A elaboração do problema e do método se desenvolvem conjuntamente, ainda que não de modo paralelo. A busca do método se converte em uma das tarefas de maior importância na investigação. $O$ método, nesse caso, é ao mesmo tempo premissa e produto, ferramenta e resultado da investigação (Vygotski, 1995, p. 47).

Vygotsky (1995) destacou o sujeito como o objeto por excelência da psicologia, mas no modo como construiu teoricamente esse problema já se encontra a influência do método, pois o sujeito é aqui concebido em sua historicidade. O materialismo histórico e dialético ocupa esse lugar na relação em que "O método tem que ser adequado ao objeto que se estuda” (p. 47). 
Desse modo, Vygotski (1995) conseguiu escapar do dualismo que marcava a crise na Psicologia, concebendo o sujeito não como subjetivo abstrato e nem como objetivo mecanicista, mas como, num movimento dialético, constituído e constituinte nas e pelas relações sociais, semioticamente mediadas (Góes, 1993; Molon, 1999; Pino, 2005; Smolka, 1993; Zanella, 2004, 2005). Por sua vez, explicitou as relações inexoráveis que existem entre o que e o como se investiga, relações essas marcadas por uma compreensão de ciência que conota o processo de produção de conhecimento e os resultados que daí advém.

\section{Sobre a relação singular/coletivo \\ e suas implicações metodológicas}

Ao propor uma mudança epistemológica/metodológica para a Psicologia, Vygotski traz como um dos principais alicerces a compreensão de ser humano como ser fundamentalmente histórico e cultural, manifestação singular de um amplo conjunto de relações sociais, indo na contramão de perspectivas que isolam o sujeito de seu contexto, pois o próprio psiquismo é constituído historicamente na complexa e indissociável relação sujeito e sociedade.

Para o autor, a compreensão dos processos psicológicos humanos mais simples se dá pela compreensão dos processos mais complexos, o que apresenta como desafio metodológico: “... mostrar na esfera do problema que nos interessa como se manifesta o grande no pequeno..." (Vygotski, 1995, p. 64), como a realidade social é recombinada e objetivada em cada pessoa que se apresenta, assim, como expressão e ao mesmo tempo fundamento dessa mesma realidade.

Nessa perspectiva, toda e qualquer análise deve buscar as relações entre os fragmentos que compõe o todo, pois os modos como esses fragmentos se relacionam, tanto os determina quanto é determinante do todo composto. Esta premissa se contrapõe a idéia de que a ordem dos fatores não altera o produto, assim como a expressão de que o todo é a mera soma das partes. Ao contrário, todo e partes unificam-se e singularizam-se, pois o todo se apresenta de alguma forma na parte que o institui e que por este é instituído. Portanto, ao se isolar os elementos, inevitavelmente os fenômenos são reduzidos, o que leva a uma análise estéril e equivocada.

... próprio sentido da análise deve ser modificado em sua raiz. Sua tarefa fundamental não é decompor o todo psicológico em partes e inclusive em fragmentos, mas destacar do conjunto psicológico integral determinados traços e momentos que conservam a primazia do todo (Vygotski, 1995, p. 99-100).

A tarefa daquele que realiza a análise é conhecer os movimentos do sujeito nas relações que este estabelece e, ao mesmo tempo, as condições dessas mesmas relações que possibilitam a emergência de algumas possibilidades para os sujeitos em relação. Afirma-se assim a mútua constituição de sujeito e realidade, pois cada pessoa é dinâmica, é síntese aberta que se realiza constantemente em movimentos de apropriação de aspectos da realidade e objetivações que modificam esta realidade.

O foco nas relações é de suma importância, pois ao isolar elementos perde-se a compreensão tanto das partes que compõe o todo, quanto da própria totalidade. Isto significa dizer que cada fragmento é constituído por meio das relações que estabelece com os demais, em movimento de mutualidade. De igual maneira compreende-se a totalidade, pois é justamente a maneira como os elementos se relacionam que configura o quadro total: qualquer mudança na composição dos mesmos, altera o todo. Vale ressaltar que o termo totalidade deve remeter sempre a uma totalidade aberta, pois a dialética leva sempre ao devir próprio do movimento. Um bom exemplo do foco nas relações, que podemos encontrar na obra de Vygotski, é a análise que $o$ autor faz da constituição do pensamento verbal, explicando que é justamente a relação entre pensamento e linguagem que, no movimento de oposição de forças, constituem-se reciprocamente e formam o pensamento verbal. (Vygotski, 1982).

A busca pelas relações é o que nos permite conhecer a transição do coletivo ao singular e deste ao coletivo, momento considerado de extrema importância na análise, pois as mudanças de qualidade se dão justamente pela realização destes movimentos: "O ponto central de nossa investigação consistirá em estudar a passagem da influência social, exterior ao indivíduo, à influência social, interior ao indivíduo e trataremos de esclarecer os momentos mais importantes que integram esse momento de transição"2 (Vygotski, 1995, p. 87).

Neste sentido, a Psicologia Histórico-Cultural caracteriza-se pela concepção da realidade como complexa, da interdependência entre fenômenos, da mútua constituição de sujeitos e sociedade. Cada aspecto contemplado na análise, nesse sentido, não é apenas mais um "apêndice" que faz parte de um todo, pois é, ao mesmo tempo, manifestação da totalidade e determinante desta totalidade, pela maneira como se relaciona com os outros aspectos. Por isso, privilegiam-se os movimentos, transições, aquilo que propicia uma compreensão integral dos fenômenos, por contemplar as relações de constituição recíproca desses e da totalidade que os mesmos compõem, e também a gênese das mudanças de qualidade propiciadas por estas íntimas relações.

\section{A História e a Dialética como fundamentos metodológicos}

Estudar os fenômenos em movimento é o mesmo que dizer que os estudamos historicamente, pois se compreende a historicidade dos processos como movimentos dialéticos, marcados por oposições, concordâncias, simetrias e 
assimetrias, enfim, tensões que se objetivam em sínteses inexoravelmente provisórias. O sujeito, nessa perspectiva, apropria-se da realidade nos aspectos que lhe são significativos, sendo a maneira como se apropria única e fundamento de sua própria singularidade.

Desta forma, a história é para a Psicologia HistóricoCultural o próprio movimento em que o sujeito, ao se apropriar, recria a realidade cotidianamente. Esse movimento por sua vez se objetiva em práticas sociais diversas que se apresentam como sínteses que contemplam aquilo que é passado no que é presente, o qual, por sua vez, se funda em um projeto de futuro, constantemente atualizado. Afirma Vygotski que: "A luz da história ilumina o presente e nos encontramos simultaneamente em dois planos: o que é e o que foi." (1995, p. 65), planos esses que dão (in)finitas possibilidades para o que pode vir a ser.

Esta historicidade é sumamente importante, pois é justamente o movimento histórico no qual o próprio sujeito ativamente participa que o constitui.

\begin{abstract}
... o estudo histórico, diga-se de passagem, simplesmente significa aplicar as categorias do desenvolvimento à investigação dos fenômenos. Estudar algo historicamente significa estudá-lo em movimento no seu desenvolvimento histórico. Essa é a exigência fundamental do método dialético. Quando em uma investigação se abrange o processo de desenvolvimento de algum fenômeno em todas as suas fases $e$ mudanças, desde que surja até que desapareça, isso implica dar visibilidade a sua natureza, conhecer sua essência, já que só em movimento o corpo demonstra que existe. Assim, a investigação histórica da conduta não é algo que complementa ou ajuda o estudo teórico, senão que constitui o seu fundamento (Vygotski, 1995, p. 6).
\end{abstract}

Desta forma, o método para Vygotski não apenas nos permite reconhecer no presente aspectos do passado, como também possibilita conhecer as especificidades da constituição do próprio sujeito, pois os processos que o constituem se dão nos próprios movimentos do sujeito em uma determinada realidade histórica que é por este singularmente apropriada. As objetivações que este realiza no mundo, tanto são produtos de apropriações passadas quanto são processos em movimento de transformação tanto de si quanto do contexto do qual é parte/partícipe, movimento este que se apresenta como em aberto, impulsionado por possibilidades de vir a ser.

\section{Princípios do método}

Ao discorrer sobre a análise das "funções psíquicas superiores", ${ }^{3}$ um dos principais objetos de estudo ao qual se dedicou, Vygotski (1995) defende a necessidade de apresentar os princípios que dão base a essa análise, e que deveriam estar presentes nas investigações psicológicas, levando-se em conta a crise metodológica da Psicologia e a premissa de história e dialética como fundamentos. Conforme o autor, "podemos assinalar três momentos determinantes sobre os quais se apóia a análise das formas superiores de comportamento e que constituem a base de nossas investigações" (Vygotski, 1995, p. 100). Assim, apresenta os seguintes princípios metodológicos:

Análise do Processo ao Invés do Objeto/Produto-Com essa proposição Vygotski se contrapôs às teorias de sua época que analisavam os objetos como formas estáveis, através da decomposição dos elementos que os constituíam.

Essa primeira diretriz relaciona-se diretamente com a perspectiva histórica e dialética a partir da qual Vygotski (1995) realiza suas investigações, pois a partir desse olhar o objeto de pesquisa não está dado e, uma vez que é constituído historicamente, se faz necessário perscrutá-lo nesse processo. Partindo desse princípio, Vygotski compreende as "funções psicológicas superiores" a partir do estudo do seu processo de desenvolvimento. Conforme o autor, “ $\mathrm{A}$ análise do objeto deve contrapor-se a análise do processo o qual, de fato, se reduz ao desdobramento dinâmico dos momentos importantes que constituem a tendência histórica do processo dado." (p. 101).

Esse direcionamento metodológico nos indica a preocupação em Vygostki frente aos problemas que estuda, uma busca pela emergência daquilo que só pode ser compreendido enquanto processo, não como algo que é, mas que está sendo a partir do que foi, inaugurando na psicologia um modo de investigar pautado numa noção dinâmica e histórica do psiquismo e do sujeito, que está relacionado com o segundo princípio metodológico que apresenta.

Análise Genotípica ao Invés de Fenotípica - Aqui o autor propõe que se busque a emergência histórica e social do fenômeno, através da análise do desenvolvimento histórico do mesmo, ao que ele se refere como a busca pelas origens genéticas de determinada função psíquica, desde que apareceu até o seu desaparecimento ou até tornar-se "automatizada". Contrapõe-se, dessa forma, aos estudos que se limitam aos aspectos imediatamente disponíveis do objeto e as suas manifestações externas. Conforme o autor, é necessário evitar o estudo de processos psicológicos fossilizados, ou seja, processos psicológicos automatizados ou mecanizados. Para tanto, faz-se necessário “... converter o objeto em movimento e o fossilizado em processo" (Vygotski, 1995, p. 105).

Para o autor, portanto, é necessário ir além do que fenotipicamente "aparece", pois esse "dado" é resultado de um processo em que se constituiu a partir de determinadas condições, históricas e sociais. Mais do que estudar o modo como algo se apresenta (um processo psíquico, ou outro objeto de estudo), se faz necessário pesquisar como pôde chegar a se apresentar do modo como se apresenta hoje, busca essa que almeja a desnaturalização dos 
fenômenos a partir de um olhar que enfoca sua historicidade e a complexidade das relações que o instituíram. $\mathrm{O}$ autor ressalta que:

... constitui um grave erro pensar que a ciência só pode estudar o que nos mostra a experiência direta... Os estudos baseados na análise de vestígios de influências, em métodos de interpretação e reconstrução, na crítica e na indagação do significado foram tão úteis quanto os baseados no método da observação "empírica” direta (Vygotski, 1996, p. 277).

A Contraposição das Tarefas Descritivas e Explicativas de Análise - Uma análise fundada nos dois princípios anteriores não se sustentaria apenas a partir da descrição. Embora reconhecesse que esta é parte importante de todo e qualquer investigação, Vygotski (1996) destaca que é necessário estabelecer teoricamente as relações que constituem o objeto que se estuda em suas múltiplas determinações. Nesse sentido, o autor também se contrapõe à psicologia subjetivista de sua época que limitava o conceito de análise científica à descrição dos fenômenos e era contrária à explicação dos mesmos. Para Vygotski a descrição por si só não é suficiente, é necessário ir além estabelecendo as relações que constituem a base de determinado fenômeno. Conforme o autor, "explicar significa estabelecer uma conexão entre vários fatos ou vários grupos de fatos, explicar é referir uma série de fenômenos a outra..." (1996, p. 216).

Nesse sentido, a perspectiva vygotskiana é explicativarelacional: o sujeito é compreendido a partir da sua condição inexoravelmente social, cultural e histórica, o pensamento em relação à linguagem (Vygostski, 1996), a criatividade em relação à memória, à imaginação, à ação, à emoção e à razão (Vygotski, 1990, 1996). Essas relações não acontecem entre fenômenos que existem aprioristicamente e então se relacionam, mas esses fenômenos só existem nas e pelas relações em que dialeticamente se constituem.

A esses três momentos apresenta-se outro princípio fundamental, a saber, a análise de unidades ao invés de elementos, princípio este que, ao contrário dos anteriores, descritos no conjunto de textos que tratam da história do desenvolvimento dos processos psicológicos superiores escritos em 1930, é explicitado no último capítulo de Pensamento e Linguagem, escrito em 1934. Vygotski se contrapõe à investigação científica pautada em elementos por fragmentarem o objeto de estudo sem atingir a totalidade do fenômeno, além do caráter não dialético desse tipo de análise. Conforme o autor, “.... a análise pela decomposição em elementos não é de fato uma verdadeira análise, aplicável à resolução de problemas concretos em qualquer tipo de fenômeno" (Vygotski, 1991, p. 288).

Em contraposição a esse método de análise característico da Psicologia subjetivista de sua época, Vygotski propõe que a análise dos processos psicológicos seja pautada em unidades de análise:

interpretando estas últimas como os produtos da análise que, diferentemente dos elementos, constituem os componentes primários, não com relação à generalidade do fenômeno a estudar, mas somente com relação às suas características e propriedades concretas. Essas unidades, diferentemente dos elementos, não perdem as propriedades inerentes ao todo que devem ser objeto de explicação, senão que encerram em sua forma mais simples e primária essas propriedades do todo que tem motivado a análise (Vygotski, 1991, p. 288).

Além dessas diretrizes, Vygotski chama a atenção para a investigação e análise de processos e condutas cotidianas automatizadas ou mecanizadas, as quais carregam as marcas de formações complexas de nossos antepassados e ao mesmo tempo anunciam devires. Novamente explicita-se sua preocupação com o caráter histórico-cultural do processo de constituição do ser humano e conseqüentemente das funções psicológicas, os quais devem ser estudados em processo.

... a valorização cotidiana de um fenômeno e seu valor de conhecimento científico nem sempre coincidem de maneira direta ou imediata e, mais ainda, não podem coincidir se tal fenômeno é estudado como prova indireta, como mínima demonstração material, como marca ou sintoma de algum processo ou acontecimento grande e importante que se reconstrói ou se desvela graças a investigação e ao estudo, a análise e interpretação de seus fragmentos ou resíduos, que se convertem em um meio valioso de conhecimento científico. $O$ zoólogo, com o resíduo insignificante de um osso animal fóssil, reconstrói seu esqueleto e, inclusive, seu modo de viver. Uma moeda antiga, que carece de todo valor real a princípio permite ao arqueólogo conhecer um complexo problema histórico. O historiador, que decifra um hieróglifo desenhado em uma pedra, penetra nas profundidades dos séculos desaparecidos. $O$ médico estabelece o diagnóstico da enfermidade com base em uns poucos sintomas. Somente nestes últimos anos a psicologia vem superando o temor diante da valorização cotidiana dos fenômenos $e$ aprende por minúcias insignificantes - resíduos dos fenômenos como dizia Freud, que pedia maior atenção para a psicologia da vida cotidiana - a descobrir com freqüencia importantes documentos psicológicos (Vygotski, 1995, p. 64).

O estudo do insignificante, também chamado por Vygotski de função rudimentar nos estudos sobre os processos psicológicos que empreendeu, é para o autor um procedimento metodológico básico para a compreensão do comportamento humano, sendo considerado o ponto de partida do método. Tem por finalidade “... revelar como 
se manifesta o grande no pequeno." (Vygotski, 1995, p. 66) Desta forma, há possibilidade de compreensão do processo histórico de transformação das funções culturais rudimentares para novas formas de comportamento, chamados de funções psicológicas superiores, já que as formas fossilizadas são o elo entre o presente e o passado. No entanto, Vygotski enfatiza que este procedimento não deve ser ponto de chegada do método, já que a investigação do insignificante não possibilita o entendimento das formações posteriores, mas garante o entendimento do movimento destas, fundamento de sua psicologia histórica. Movimento entre o começo e o fim do desenvolvimento, entre a plasticidade e a petrificação, entre o que foi, o que é e o que pode vir a ser.

\section{Busca dos sentidos: unidade de análise para a Psicologia Histórico-Cultural?}

Além das contribuições sobre método aqui apresentadas, Vygotski (1991), ao discutir em sua última obra as relações entre pensamento e fala, de certa forma retoma as reflexões anteriores sobre as relações dialéticas entre coletivo e singular, sujeito e cultura, apresentando-as sob a égide de uma unidade, a saber, os significados ou sentidos. Embora estabeleça uma diferença entre esses dois conceitos - o primeiro é necessariamente compartilhado e goza de uma relativa estabilidade, provisória em razão de sua condição social e histórica; os sentidos, por sua vez, referem-se a uma dimensão essencialmente idiossincrática - o próprio Vygotski os unifica quando afirma que "o sentido da palavra é a soma de todos os eventos psicológicos evocados em nossa consciência graças à palavra. $\mathrm{O}$ significado é só uma dessas zonas do sentido, a mais estável, coerente e precisa" (1991, p. 333).

Significados e sentidos, por sua vez, são produzidos por sujeitos em suas complexas relações, via atividade que é marcada pelas trajetórias e experiências de cada um e de todos e ao mesmo tempo pelas condições e características do contexto histórico em que vivem. Desse modo, toda e qualquer atividade humana foco de investigação psicológica requer, para sua compreensão e explicação, o olhar sobre os sentidos que têm para os sujeitos em relação, olhar esse que considere a indissociabilidade de sujeitos, de suas condições de possibilidades e a realidade histórica do contexto do qual ativamente participam.

Essa assunção é possível como decorrência da afirmação de Vygotski de que:

... o sentido da palavra é ilimitado. A palavra ganha sentido no contexto da frase, mas a frase ganha sentido, por sua vez, no contexto do parágrafo, o parágrafo o deve ao contexto do livro e o livro o adquire no contexto de toda a criação do autor (1991, p. 333-334).

Toda palavra é, por sua vez, uma generalização, e como tal um fenômeno do pensamento, que se interconecta com a memória, a percepção, a imaginação, enfim, com todos os processos psicológicos e a dimensão afetivo-volitiva que move as pessoas e conota as relações que estabelece com outros e consigo mesmas.

A transformação do pensamento em palavra, por conseguinte, é um processo complexo e dinâmico de decomposição e recomposição, de transformações complexas onde a objetivação do sujeito por meio da palavra escrita ou falada, do gesto, da expressão, nunca corresponde diretamente ao pensamento que a engendrou e que é modificado no próprio processo de comunicação. Dito de outra forma, há sempre um subtexto oculto em todo enunciado. Desse modo, o pensamento não é simplesmente expresso em palavras ou outro signo pelo qual se objetiva, ele se constitui por meio deles, tanto em sua dimensão física, ou seja, pelo som, traço ou imagem que o apresenta, quanto pelos sentidos produzidos nos contextos de interlocução, sentidos esses que pressupõem necessariamente algum outro, presente ou ausente: "Se tudo que desejamos expressar estivesse contido nos significados formais das palavras empregadas, para expressar cada pensamento distinto necessitaríamos utilizar muito mais palavras do que na realidade empregamos. Falamos somente com as alusões necessárias" (Vygotski, 1991, p. 323).

Se, por sua vez, esse processo de transição do pensamento para a fala é complexo e dinâmico, podemos afirmar que, mais do que alusões necessárias, as falas são expressões das (im)possibilidades do sujeito nos processos de comunicação, (im)possibilidades essas que transcendem as intencionalidades e constituem a arena das interlocuções em que um e outro se apresentam como referências e ao mesmo tempo limites para o que se diz ou se deixa de dizer. Eis aqui outras implicações metodológicas que $\mathrm{Vy}$ gotski de certa forma anuncia, porém não desenvolve. $\mathrm{O}$ pensamento, assim como o próprio sujeito, é mescla intrincada de cognição e afetos, de razão e desrazão, que no próprio processo de se objetivar - seja via palavra, expressão, gesto, escrita, ou outro - concomitantemente se (re)constitui. O próprio movimento de objetivação, se não direto, imediato, apresenta-se como processo de criação e, enquanto tal, não é necessariamente tranqüilo, o que Vygotski (1990) se refere como torturas da criação.

Neste sentido é que Vygotski (1991) chama a atenção ao fato de que para a compreensão da linguagem do outro é necessário ir além das palavras, buscando também o pensamento que a constitui e sua motivação, já que por trás de cada pensamento há uma intenção afetivo-volitiva. Desta forma, na investigação da linguagem a busca dos sentidos se torna fundamental para Vygotski, posto que o sentido é expressão dialética dos planos singular e coletivo.

Por sua vez, ao destacar a dimensão dos afetos e da vontade, não necessariamente (re)conhecidos e apresentados em uma linguagem clara, tanto pelo/para o sujeito 
da ação quanto um outro, Vygotski de certa forma reconhece a complexidade de toda e qualquer investigação onde pessoas em relação se apresentam como foco. Afinal, na dimensão dos sentidos, essencialmente polifônica e polissêmica, apresentam-se muito mais do que intencionalidade e clareza, há o efêmero, o imprevisto, o plural, $\mathrm{o}$ acontecimento em si, enfim, a própria existência em processo, constante devir.

\section{Considerações Finais}

Pesquisar é uma atividade complexa que vem sendo reconhecida em sua dimensão plural, ${ }^{4}$ o que aponta para a necessária reflexão sobre a adequação do método ao que se investiga. Nesse sentido, as contribuições metodológicas de Vygotski são aqui apresentadas em razão de sua atualidade e pertinência, posto o reconhecimento por parte deste autor da inexorável relação entre o que é objeto de pesquisa, os caminhos trilhados na investigação e a produção de conhecimentos daí decorrente, aspectos esses amalgamados pela orientação teórico-epistemológica assumida pelo pesquisador, seja de modo explícito ou não.

É possível identificar na obra de Vygotsky, ainda que marcada por problemáticas e o léxico da época em que viveu, essa unidade na diversidade: discutiu vários assuntos, como a história da psicologia, criatividade, reação estética, o desenvolvimento dos processos psicológicos superiores, porém em todas as suas produções destaca-se a questão da constituição social e histórica do psiquismo humano como centro de seus interesses. Em outras palavras, a pessoa em sua humanidade, essencialmente histórica e cultural, se apresenta como foco, sendo a diversidade de possibilidades metodológicas demarcadora de uma postura aberta ao reconhecimento da complexidade de sujeitos e realidade e de sua condição histórica e plural. Ao pesquisador, por fim, cabe produzir explicações que possibilitem conhecer essa realidade em seu fluxo e ao mesmo tempo problematizar o que aparece como um possível dentre a infindável gama do que é e do que pode vir a ser.

\section{Notas}

1 A busca restringiu-se a produções científicas, a partir do ano 2000, que utilizavam os descritores Vygotsky, Vygotski, Vigotsky e Vigotski como palavras-chave, com exceção da base de dados Google Shoolar Beta que não fornecia esta opção de busca. Neste caso, restringiu-se a pesquisa para o título das produções.

2 Essa passagem, embora importante na medida em que explicita o caráter inexoravelmente social do que se apresenta como singular, é motivo de polêmica na medida em que veicula uma certa dicotomia entre externo e interno, entre social e singular. A partir da própria teoria de Vygotski é possível compreender a dialeticidade dessas dimensões, explicitadas por Pino (2000) e Zanella (2005).
O conceito de "Funções Psicológicas Superiores" refere-se, segundo Vygotski, aos processos psicológicos semioticamente mediados. Neste sentido, ao utilizar o termo "funções" não o faz ancorado em pressupostos biologicistas, funcionalistas e/ou estruturalistas, mas refere-se a processos que se dão no plano da cultura, que se fazem e refazem constantemente (Pino, 2000).

4 Ver por exemplo as discussões de vários pesquisadores, compiladas por Boaventura de Souza Santos (2006).

\section{Referências}

Davis, C., \& Oliveira, Z. (1994). Psicologia na educação. São Paulo, SP: Cortez.

Giest, H. (2004). The formation experiment in the hypermedia and distance learning. European Journal of Psychology of Education, 19(1), 45-64.

Góes, M. C. R. de. (1993). Os modos de participação do outro nos processos de significação do sujeito, Temas em Psicologia, 1 .

Holzman, L. (2006). Activating postmodernism. Theory Psychology, 16(1), 109-123.

Kramer, S., \& Souza, S. J. de. (1991). O debate Piaget / Vygotsky e as políticas educacionais. Cadernos de Pesquisa, 77, 69 - 80.

Lúria, A. (1988). Pensamento e linguagem: As últimas conferências de Lúria. Porto Alegre, RS: Artes Médicas.

Molon, S. I. (1999). Subjetividade e constituição do sujeito em Vygotsky. São Paulo, SP: EDUC.

Pino, A. L. B. (1992, ago.). As categorias de público e privado na análise do processo de internalização. Educação \& Sociedade, 42.

Pino, A. L. B. (2000). O social e o cultural na obra de Lev S. Vigotski. Educação \& Sociedade, Campinas, 71, 45-78.

Pino, A. L. B. (2005). As marcas do humano. Às origens da constituição cultural da criança na perspectiva de Lev S. Vigotski. São Paulo, SP: Cortez.

Santos, B. S. (2006). Conhecimento prudente para uma vida decente: Um discurso sobre as ciências revisitado. São Paulo, SP: Cortez.

Shotter, J. (2000). Seeing historically: Goethe and Vygotsky's 'enabling theory-method'. Culture and Psychology, 6(2), 233-251.

Smolka, A. L. B. (1993). Construção de conhecimento e produção de sentido: Significação e processos dialógicos. Temas em Psicologia, Ribeirão Preto, 7-15.

Vygotski, L. S. (1982). Pensamiento y palabra. In Obras Escogidas: Vol. 2. Madrid, España: Visor.

Vygotski, L. S. (1990). La imaginación y el arte em la infância (2. ed.). Madrid, España: Akaal.

Vygotski, L. S. (1991). Obras Escogidas: Vol. 2. Problemas de Psicología General. Madrid, España: Visor.

Vygotski, L. S. (1995). Obras Escogidas: Vol. 3. Problemas del desarollo de la psique. Madrid, España: Visor.

Vygotski, L. S. (1996). Teoria e método em Psicologia. São Paulo, SP: Martins Fontes.

Zanella, A. V. (2004). Atividade, significação e constituição do sujeito: Considerações à luz da Psicologia Histórico-Cultural. Psicologia em Estudo, Maringá, 9(1), 127-135.

Zanella, A. V. (2005, maio/ago.). Sujeito e alteridade: Reflexões a partir da Psicologia Histórico-Cultural. Psicologia \& Sociedade; 17(2), 99-104. 
Andréa Vieira Zanella é Professora Doutora do Programa de Pós-Graduação em Psicologia da Universidade Federal de Santa Catarina (UFSC) e bolsista produtividade CNPq. Endereço para correspondência: UFSC, CFH, Departamento de Psicologia, Campus Universitário, Trindade, Florianópolis, SC, 88040-970. azanella@cfh.ufsc.br

Alice Casanova dos Reis é Mestre em Psicologia pela UFSC. alicecasanova@yahoo.com.br

Andréia Piana Titon é Mestranda em Psicologia pela UFSC e bolsista Capes. andreiatiton@yahoo.com.br
Lílian Caroline Urnau é Mestranda em Psicologia pela UFSC e bolsista Capes.

lilianurnau@yahoo.com.br

Tais Rodrigues Dassoler é Mestranda em Psicologia pela UFSC e bolsista Capes.

taisdassoler@hotmail.com

Questões de Método em textos de Vygotski: contribuições à pesquisa em Psicologia

Andréa Vieira Zanella, Alice Casanova dos Reis, Andréia Piana Titon, Lílian Caroline Urnau e Tais Rodrigues Dassoler Recebido: 31/01/2007

Aceite final: 26/03/2007 